Running head: A LEXICAL ANALYSIS OF LOVE

\title{
The flavours of love: A cross-cultural lexical analysis
}

Dr. Tim Lomas, University of East London, School of Psychology, t.lomas@uel.ac.uk 
Running head: A LEXICAL ANALYSIS OF LOVE

\begin{abstract}
Linguists have often remarked upon the polysemous nature of love, whereby the term encompasses a wide diversity of emotional relationships. Several typologies have been constructed to account for this diversity. However, these tend to be restricted in scope, and fail to represent the range of experiences signified by the term 'love' in discourse. In the interest of generating an expanded typology of love, encompassing its varied forms, an enquiry was conducted into relevant concepts found across the world's cultures, focusing on so-called untranslatable words. Through a quasi-systematic search of published and internet sources, 609 relevant words were identified. These were organised through a version of grounded theory into 14 categories, representing 14 different types of love. The result is an expanded theoretical treatment of love, allowing us to better appreciate the nuances of this most cherished and yet polysemous of concepts.
\end{abstract}

Keywords: love; linguistics; theory; typology; cross-cultural 
Few experiences are as cherished as love, with surveys consistently reporting it to be among the most sought-after and valorised of human emotions (Wilkins \& Gareis, 2006). At the same time though, few concepts are as contested, with the label encompassing a vast range of phenomena - spanning diverse spectra of intensity, valence, and temporal duration, and being used in relation to a panoply of relationships, objects and experiences. Indeed, Murstein (1988, p.33) described love vividly as "an AustroHungarian Empire uniting all sorts of feelings, behaviors, and attitudes, sometimes having little in common." As such, while most words are polysemous, linguists suggest that love is "polysemous in the extreme," as Berscheid (2010, p.6) puts it.

Given its polysemous nature, scholars have attempted to create theoretical typologies of different forms of love. One early and particularly influential effort was by John Lee $(1973,1977)$, who drew on distinctions elucidated in the classical age to identify six 'styles' of loving. (Five of these types were adapted from classical Greek, while the sixth, ludus, is Latinate.) Lee suggested there were three 'primary' forms of love: érōs (romantic, passionate), ludus (flirtatious, playful), and storgē (filial, fraternal, companionate). By pairing these, three further types arose from the permutations: prâgma (rational, sensible - a combination of ludus and storgē), mania (possessive, dependent - a combination of érōs and ludus), and agápē (charitable, selfless - a combination of érōs and storgē). Lee's typology subsequently received experimental validation, particularly from Hendrick and Hendrick (1986), who devised a 42-item self-report scale and corroborated the six factor structure through factor analysis. Further work then sought to elucidate patterns of association between the types and other factors, For instance, exploring personality attributes, Mallandain and Davies (1994) reported that self-esteem was positively correlated with érōs, and negatively with mania, storgē and agápē. Conversely, emotionality and impulsivity were both positively linked to mania and ludus, while emotionality was negatively associated with érōs. 
Around the same time, an alternative theoretically-derived typology was developed by Robert Sternberg (1986). His 'triangular' theory of love suggested it arises from the presence and interaction of three principle components: intimacy, passion, and decision/commitment. Their permutations then give rise to seven types of love: liking (intimacy alone); infatuated love (passion alone); empty love (commitment alone); romantic love (intimacy and passion); companionate love (intimacy and commitment); fatuous love (passion and commitment); and consummate love (all three). As with Lee (1977), Sternberg also developed his model into a psychometric scale, for which he obtained a measure of factor analytic validation. Likewise, there were empirical efforts to link his types of love with other psychological processes and outcomes, such as personality. For instance, examining the model's relationship to Costa and McCrae's (1992) 5-factor model, Engel, Olson, and Patrick (2002) found that of all the five factors, conscientiousness was - perhaps surprisingly - the strongest predictor of love (for both passion and intimacy in males, and for commitment in females), while factors such as agreeableness appeared to have no particular relation. (The authors speculated that this may be because conscientiousness is associated with people having the drive and skill to 'work at' relationships, which may be a precondition of lasting love.)

However, given that the two models do not totally overlap, arguably each is somewhat incomplete or partial. It would appear that the theories only have one definite primary element in common, where Sternberg's (1986) passion component can perhaps be equated with Lee's (1977) notion of érōs. Beyond this, there are some close parallels; for instance, Sternberg's primary component of commitment can possibly but incompletely be equated with Lee's primary type of storgē, and perhaps also with the secondary type of prâgma. Then there are elements that appear specific to one model only: Sternberg's primary component of intimacy does not map easily or exclusively on to any of Lee's styles, whereas Sternberg does not view ludus and prâgma as types of love (Shaver \& Hazan, 1988). 
However, one could further argue that, even taking the two models together, these do not exhaust the polysemous nature of love. In particular, both models tend to mainly depict different varieties of romantic relationships, i.e., between two people who identify as being 'partners.' There are therefore many different uses of the word love that are not represented by these models.

For instance, a person might speak of their love for their country, or swimming, or a Mozart symphony, or ice cream, or their cat, and so on. These types of love are an awkward presence in the context of the models above, where it becomes necessary to either, (a) deny that these forms strictly constitute love per se, or (b) stretch the models uneasily so that their romantically-inclined styles of love extend into unusual areas. An example of the former is work around brand loyalty by Shimp and Madden (1988), who adapted Sternberg's (1986) work to formulate a conceptual model of 'consumer-object relationships,' in which Sternberg's components are reconfigured as liking, yearning, and decision/commitment. In a similar consumer context, a case of (b) can be found in Whang, Allen, Sahoury, and Zhang (2004), who directly apply Lee's (1977) components to a motorcycle, suggesting that bikers genuinely feel érōs, mania and agápē in relation to it. However, without denying the value and validity of such studies, they appear to be straining to make the data - the real-world phenomena - fit the theory.

Part of the problem stems from the fact that both Lee (1977) and Sternberg (1986) formulated their models on the basis of only three primary components. This necessarily limits the permutations that can be derived to six or seven (depending on whether one allows a permutation of all three, as Sternberg does). However, there is no a priori reason that love should only comprise three such components. Indeed, as this paper will show, it is possible to identify at least three further candidates that merit the status of 'primary' components: care; connection; and appreciation. These could be considered primary in that their presence alone 
- in the absence of Lee's or Sternberg's primary components - warrant 'legitimate' uses of the word love. For instance, I may experience a surge of compassionate yet abstract love towards humanity 'in general.' This love is not characterised by any of Sternberg's trio of passion, intimacy or commitment, nor Lee's trio of érōs, ludus and storgēe, but rather is an expression of care. Likewise, one might love a certain novelist due to a feeling of shared sensibilities, or love a possession - a painting, say - based on its aesthetic properties. Neither example requires Lee's or Sternberg's primary components, but instead involve connection and appreciation respectively. All these cases are genuine and indeed familiar examples of the way 'love' gets used in common discourse; as such, any comprehensive theory of love ought to be able to accommodate these. To this end, this paper seeks to develop an expanded taxonomy of love, doing so through the innovative device of exploring 'untranslatable' words, as the next section outlines.

\section{Untranslatable words}

This paper draws on recent work by Lomas (2016), who is developing a lexicography of untranslatable words. While untranslatability is a contested phenomenon, it essentially refers to a word that appears to lack an exact equivalent in a given other language (in the present case, English). The interest in such words is manifold.

First, they can assist in understanding other cultures, offering insights into their values, conceptualisations, traditions, and ways of being (Wierzbicka, 1999). The theoretical context here is the Sapir-Whorf hypothesis - developed by Sapir (1929) and Whorf (1940) which holds that language influences how people experience, understand, and perceive the world. The stronger version of this hypothesis is linguistic determinism, whereby language inextricably constitutes thought. By contrast, the milder version simply asserts that language shapes thought and experience. In relation to untranslatable words, the stronger deterministic view holds that only people enmeshed within the culture that produced a given word can truly 
understand or experience the phenomenon that the word refers to. Conversely, the milder relativistic perspective suggests that such words are to an extent accessible to people outside the culture, holding some potential universal relevance.

This latter point highlights a second element of interest regarding untranslatable words. Beyond just being informative vis-à-vis the culture that created them, such words can enrich other lexicons. This phenomenon of cultures 'borrowing' words is central to language development. Indeed, of the more than 600,000 lexemes in the Oxford English Dictionary, the percentage of borrowed words is estimated to be as high as $41 \%$ (Tadmor, 2009). Such borrowings are known as 'loanwords,' although more specific terminology has also been developed to reflect varying levels of assimilation into the host language. In fact, we can see this very process at work in Lee's (1977) typology, where he retained the classical words in their original form, rather than seeking an approximate English equivalent (as Sternberg sought to).

Of particular interest here is why words are borrowed. Haspelmath (2009) identifies two main reasons: core versus cultural borrowings. Core borrowings are when a loanword replicates a word that already exists (i.e., with a similar meaning) in the recipient language. The tends to happen for sociolinguistic reasons, e.g., cultural capital associated with using foreign words (Blank, 1999). This type of borrowing is not of concern here. However, the second category of cultural borrowing is central. Haspelmath refers to these as 'loanwords by necessity,' where the recipient language lacks its own word for a particular referent. Thus, the loanword is used for pragmatic reasons: it is cognitive and socially useful, allowing speakers to articulate concepts they had previously been unable to. In Lehrer's (1974, p.105) terminology, such words fill 'semantic gaps,' i.e., "the lack of a convenient word to express what [one] wants to speak about." It is such semantic gaps that makes a word untranslatable, 
suggesting the existence of phenomena that have been overlooked or undervalued by one's own culture, but which another culture has noticed, identified and labelled.

Thus, a central premise of Lomas' (2016) lexicography is that such words can enrich the English lexicon, and moreover enhance the nomological network in psychology. There are numerous reasons why that would be desirable, most notably the critique that academic psychology tends to be Western-centric (Becker \& Marecek, 2008; Lomas, 2015a). As a result, one could argue that the current nomological network in psychology is incomplete, having been largely founded upon concepts that happen to have been identified in English. The aim of the lexicography is therefore to augment this network with constructs which have not yet been identified, as signalled by the existence of an untranslatable word. Clearly, there is a wide range of phenomena that could potentially be of interest. As such, to narrow down the focus of the lexicography to a manageable area of enquiry, its focus is on wellbeing specifically. A key aspect of this love, which constitutes one of the six core thematic categories in the lexicography. (The other five are positive emotions (Lomas, in press c), ambivalent emotions (Lomas, in press a), spirituality (Lomas, in press b), prosociality, and character development.) Thus, the current paper aims to provide a more comprehensive understanding of this topic through the study of relevant untranslatable words.

\section{Methods}

In order to develop a more extensive typology of forms of love, following the example of Lomas (2016), a quasi-systematic review of untranslatable words pertaining to love was undertaken. As per the original paper, it is quasi-systematic in that there was insufficient source material in academic journals, meaning that a conventional systematic review, utilising standard academic databases, was not feasible. The review involved several stages.

The first stage involved searching for relevant words. This stage featured two main search strategies. First, 30 websites and blogs devoted to untranslatable words were explored. 
These were located by entering "untranslatable words" into google, and picking the first 30 such websites and/or blogs. Examining these, any word pertaining to love was selected, using love in an expansive sense to incorporate diverse spectra of intensity, valence, and temporal duration, and in relation to a wide variety of relationships, objects and phenomena. This search strategy generated 97 words. Second, there was a process of searching google one language at a time. This involved entering “ concept of" and "love" into the search engine, with a different language in the underlined space each time. Proceeding through the first ten pages for each search, there was an effort to identify words relating to love that were presented as being unique to a particular culture. This generated a further 512 words, mainly because of a vast number of constructs created - often as recent neologisms - via the prefix 'philo-' or the suffix '-philia' (with one website alone featuring 457 such words). As a result, 609 potentially relevant terms were located. However, around three-quarters of these were the various 'philo-/-philia' derived terms. While these were not discounted, they were not prioritised, since it is theoretically possible to construct such terms with respect to any phenomenon. Moreover, in contemporary usage, many philia words are used to delineate unusual or deviant sexual proclivities, which is tangential to the purposes of this paper.

Having compiled a list of words, they and their descriptions were checked for accuracy by consulting online dictionaries, as well as peer-reviewed academic sources (if such were available for a given word). The words were then analysed using grounded theory (GT) (Strauss \& Corbin, 1998), a qualitative methodology which allows theory to emerge inductively from the data. GT involves three main stages: open coding, axial coding, and selective coding. First, open coding involves examining the data - which in this study was the list of words - for emergent themes. As noted above, priority was given to the 152 words which were not a type of 'philo-/-philia.' The words were examined carefully for their thematic content. The next stage was axial coding, in which the words were grouped together 
into categories based on their thematic similarity. Here, 14 separate categories - 14 types or 'flavours' of love - were identified, as outlined below. (The use of the term 'flavours' is to avoid the implication that a given relationship necessarily just constitutes one of these types exclusively. It is possible that a romantic partnership, say, might be a blend of multiple flavours, and moreover that this mix may change dynamically over time.) For the purposes of consistency, each category was labelled using one of the Greek words placed it. The final GT stage is selective coding, in which a single core category is identified, which in this case was love. Attempts are then made to elucidate how the main categories relate to this core category, thus telling a narrative which makes sense of the data. The 14 categories (or 'types' or 'flavours') are introduced in turn below, including a sample of the words that helped shape the category.

\section{Results}

The first three categories pertain to love not oriented towards people per se, but towards other phenomena. This in itself distinguishes the approach here from Lee (1977) and Sternberg (1986), who restricted themselves to love of people. Obviously, it is possible to love, or to be drawn towards, a bewildering array of non-human phenomena, as attested to by the many hundreds of words coined using the philia prefix, from ablutophilia (relating to bathing) to zoophilia (relating to animals). However, it was possible to group these phenomena into three main forms - experiences, objects, and places - which thus constitute the first three categories outlined below. The remaining 11 categories depict forms of love relating to other people, featuring the six types identified by Lee, together with five additional types.

\section{Meraki: Experiential love}

The first 'non-personal' category is a love of activities and experiences. This is a catch-all category for a deep fondness for any type of action or endeavour, from ambulophilia (love of walking) to gephyrophilia (love of crossing bridges). It should right away be emphasised that 
in classical Greece, philia did not signify anything sexual per se, as indeed neither does it necessarily today (as per, for instance, Francophilia, a love or admiration for France). The term selected to represent this all-encompassing class of experiences is the Greek verb (and sometime adverb) meraki. This could be loosely translated as ardour, specifically with respect to one's own actions and creations. As a verb, meraki can express desire or longing for a specific activity, whereas as an adverb, one might undertake a task with a spirit of ardour, care and love. Besides the various philias that fall within the ambit of this term, other words helped shape this category. Some capture a passion and zest for life generally, including the Spanish nouns duende and vivencia, and the French phrase joie de vivre, with the latter an excellent example of an untranslatable phrase that has already been imported into English. Other words denote appreciation or fondness for specific activities. For instance, numerous words extoll the virtue of savouring aspects of nature, such as the Japanese noun shinrin-yoku which refers to the therapeutic act of 'bathing' in the quietude of a forest (figuratively and/or literally).

\section{Érōs: Aesthetic love}

The second non-personal category pertains to a love of objects, from physical items (e.g., a work of art) to abstract concepts (as reflected in philosophy, literally the love of wisdom). As with meraki, this category encompasses a wide range of philias. This time though, the love is for the 'object,' rather than the experience of engaging with it. This is the type of affection alluded to in the aforementioned research exploring love for consumer brands (Albert, Merunka, \& Valette-Florence, 2008). Selecting an apposite Greek term to represent this form of love was tricky, due to ambiguities and shifts in the meaning of terms over time and across contexts. Ultimately, érōs was selected, though not without reservations. In classical usage, the term tended to denote desire, often - but not exclusively - for people. Moreover, it did not specify sexual desire, as it frequently tends to today (hence the reservation over its selection). 
Rather, in the writings of Plato and others, it was more commonly invoked in the context of aesthetic appreciation of beauty, in which one loves an object because it partakes in the perfection of the divine Forms/Ideas. As Plato writes in Phaedrus (249E): "he who loves the beautiful is called a lover because he partakes of it" (cited in Hofstadter \& Kuhns, 2009, p.61). Thus, érōs is used here to capture a strong appreciation or yearning for non-personal phenomena, with sexual desire instead represented by epithymia below.

\section{Chōros: Rooted love}

The third 'non-personal' category is love of particular places, and especially the feeling of being rooted in such places. One might regard this as a potent combination of meraki and érōs, in that one might love a place due to a combination of the 'objects' (including people) and experiences associated with it. The word selected for this category is choros, one of two main words used in classical Greece to refer to a place, alongside topos. As elucidated by Walter (1988, p.120), whereas topos generally referred to the layout of a place, writers such as Ptolemy (90-168 CE) would use chōros signify its quality, and moreover the affection and significance attached to it. Sometimes such affection would be denoted through the philia suffix (i.e., chōrophilia), but this sense was retained when the suffix was omitted, such that a sacred place might be termed a chora. In the present analysis, this category was formed through the identification of various conceptually similar words - all valued in their respective cultures - that describe a deep, heartfelt connection to certain locales, particularly one's homeland. These include toska, hiraeth, and saudade, which articulate a complex sense of belonging and/or yearning that are specifically tied to Russia, Wales, and Portugal/Brazil respectively (Wierzbicka, 1999). For instance Coupland, Bishop, and Garrett (2003, p.164) define hiraeth as "a Welsh cultural longing for Wales," and discuss how it is intimately connected to feelings around cultural heritage and national identity. Not all relevant words 
Running head: A LEXICAL ANALYSIS OF LOVE

pertain to one's homeland though; for instance, German has Fernweh and Wanderlust to depict a desire to travel to, or the "call of," distant places (Gabriel, 2004, p.155).

\section{Philia: Friendly love}

Turning to the first form of love directly specifically towards people, there is the 'Platonic' love that defines close friendship, denoted here by the label philia. Of course, as has been noted already, philia is a contested, polysemous term, used in multiple ways. In classical Greece, it tended to depict fondness, appreciation and loyalty - in contrast to the passionate desire and yearning of érōs - which might not only be bestowed upon friends, but also one's family, job, community and country (Hofstadter \& Kuhns, 2009). By contrast, in contemporary usage, as a suffix it is sometimes (though by no means always) used to represent sexual desire. However, its selection here is guided by its usage in classical Greece, particularly Aristotle's emphasis on friendship. This is exemplified by his description of 'things that cause friendship' in Rhetoric as being; "doing kindnesses; doing them unasked; and not proclaiming the fact when they are done" (Aristotle, 1954, II. 4). Nestled within this category are various other words which pertain to close, affectionate friendship. For instance, Greek also includes the derivation philotimo, a culture-defining characteristic of respecting and honouring one's friends. Similarly, friendships imbued with Platonic love are captured by terms like cariño and confianza in Spanish.

\section{Philautia: Self love}

There is one form of philia which does warrant its own category, since it is not a love of others, nor of experiences, objects or places. Rather, it is the unique phenomenon of loving oneself. As with the three non-personal types of love above, this does not sit easily within Sternberg's (1986) conceptual triad of intimacy, passion and commitment. Rather, we are concerned here with various positive qualities prefixed by the term self, including -esteem, compassion, -regard, and -respect. Indeed, Aristotle argued in the Nichomachean Ethics that 
this was the precondition for the other forms of love (NE, IX.8). However, the term philautia admits positive and negative varieties. Aristotle was referring to its more benevolent type, a secure form of self-esteem in which this self-regard is not at the expense of other people (who are equally respected and cherished). His ideal of self-love is a reflective pursuit of virtue, and the desire to cultivate one's character, to thereby be better able to extend affection and help to others. By contrast, its darker variant encompasses notions such as narcissism, arrogance and egotism. (Indeed, narcissism itself is an untranslatable word of sorts, derived from the legend of the self-absorbed Narcissus.) In a related, but slightly different way, French has two words for self-love. Held in higher regard by the likes of Rousseau (1762) is amour de soi, literally 'love of oneself,' which depicts self-esteem that is unconditional and secure (Cooper, 1998). On the other hand, amour proper, or 'self-love,' is comparatively fragile and contingent on the validation of others.

\section{Storgēe: Familial love}

The next category is storge, which in classical Greece depicted care and affection, usually between family members (Isaacs, 2015). For instance, Browning (2002, p.335) describes it in terms of the 'deep and preferential investment by parents' in their children. Admittedly, there is a fuzzy boundary between storgē and philia - as there is between many categories here given that some friendships can be so close that the person is essentially considered family. Indeed, in Lee's (1977) typology, storgē was characterised more as a companionate love. Nevertheless, it is useful to differentiate between the love one may have for one's closest friends, and the kind of deep familial love that can exist between kin (Montgomery \& Sorell, 1997). In terms of the words uncovered in the analysis, storge e is captured by the verb kanyininpa, from the Aboriginal Pintupi language. Myers (1991) suggests it refers to "an intimate and active relationship between a "holder" and that which is "held,"” capturing the deep feeling of nurturance and protection a parent usually feels for a child (p.146). Such love 
is quite different to the companionship between friends, encompassing powerful sentiments of care, protection, and unconditional (i.e., non-contingent) responsibility.

\section{Epithymia: Passionate love}

We now move into the first of five categories pertaining to what might be called 'romantic' love. (One should note though that romantic relationships may also involve some of the other 'flavours' included in the typology, particularly storgē and philia.) Romantic love refers generally to the more or less exclusive bond - with some exemptions, like polygamy between two people who identify as 'partners.' This first type, epithymia, pertains to passionate love, encompassing qualities such as sensual desire and physical attraction. In Lee's (1977) and Sternberg's (1986) theories, passion was one of the three primary forms of love (labelled by Lee as érōs). However, epithymia is preferred here, enabling érōs to be used more generally for non-sexual appreciation and desire, as outlined above. For instance, Tillich (1954) argues that érōs 'transcends' epithymia, precisely because érōs is not merely about basic physical desire, but is imbued with higher values (e.g., an appreciation of beauty). An alternative title for this category was erotikos, as per Plutarch's dialogue on passion of that name (more commonly referred to as the Amatorius) (Brenk, 1988); however, epithymia arguably renders the distinction with érōs clearer. As with the other categories, various words pertained to this feeling. For instance, in Chilean Yagán, mamihlapinatapei refers to a look between people that expresses unspoken but mutual desire, while in Tagalog, kilig captures the butterflies in the stomach arising from an interaction with (or a thought of) someone one desires or finds attractive.

\section{Paixnidi: Playful love}

The second category of romantic love is labelled here as paixnidi. This was one of Lee's (1977) three primary forms of love, for which he used the Latin cognate, ludus. However, for consistency, the Greek paixnidi is preferred here. Both are nouns, meaning game or play. 
Moreover, both are multifaceted, capable of being deployed in positive or negative ways. In their positive inflection, they can refer to playful gestures of flirtation, to coy, game-based strategies (e.g., playing 'hard to get'), or to cheeky displays of affection. An example of the latter is found in Tagalog, where gigil describes the irresistible urge to pinch/squeeze someone because they are loved or cherished. At a deeper level, in Western contemplative mystery traditions, the phrase ludus amoris depicted the divine play of God, in which God eludes and yet also entices the spiritual seeker (Underhill, 1941). Comparable concepts, and concomitant terms, are found in other traditions, such as the Hindu notion of lila (Kinsley, 1974). However, paixnidi and ludus can also have negative connotations, such as describing scheming and deception in relation to love. Indeed, many studies drawing on Lee's typology emphasise this darker 'gamefulness' (rather than a more benevolent 'playfulness'). For instance, Sarwer, Kalichman, Johnson, Early, and Ali (1993, p.265) define ludus as “a manipulative, game-playing orientation towards intimate relationships," finding that this was the best predictor of coercion among Lee's six styles. This negative side of paixnidi/ludus is reflected in the Boro verb onsay, which has been rendered as 'to pretend to love.'

\section{Mania: Possessive love}

Related to the negative aspects of paixnidi/ludus is mania, the darkest category of love in this typology. Mania is already a loanword of course, but was also specifically deployed by Lee (1977) as one of his three secondary styles, a possessive, dependent form of love arising from a noxious combination of érōs (as Lee deployed the term) and ludus. It has its parallel in Sternberg's (1997) notion of 'fatuous/infatuated love,' which he conceived as a problematic conjoining of passion and commitment (thus minus intimacy). A modern English equivalence might be 'limerance,' coined by Tennov (1998) to depict this intense, somewhat unstable feeling. Similarly, it has been conceptualised by Sperling and Berman (1991) as 'desperate love,' and by Hindy and Schwarz (1994) as 'anxious romantic attachment.' This type of love 
has its versions among the words/phrases analysed here, like the French notion of amour fou, which literally translates as 'mad love.' Indeed, scholars have argued that this darker form of love is worryingly common, in which positive feelings are intermingled with emotions like anger, jealousy and anxiety, to the extent that Spitzberg and Cupach (1998) claim provocatively - in their book The Dark Side of Close Relationships - that "love and hate are indeed impossible to disentangle" (p.xiii).

\section{Prâgma: Rational love}

Standing in contrast to the intensity and instability of mania is prâgma. This was another of Lee's (1977) secondary styles, a rational, sensible form of love arising from the conjunction of ludus and storgē. It has a tenuous parallel with Sternberg's (1997) notion of 'empty' love, which consists of commitment only. However, the pejorative qualifier 'empty' - implying a partnership in which people stay together, but feel no 'love' (e.g., intimacy) for each other fails to capture the nuances embedded within prâgma. The term can be translated as a deed, action, or 'a thing done.' It thus captures the sense that love is not only the swooning feeling of 'falling' for someone, but also consists in the long-term process of building a life together, of forging a bond that does not depend upon the passing whims of desire. This aspect of love is often overlooked, or is not even regarded as love per se, as implied by Sternberg. However, its value has been recognised by theorists such as Fromm (1956), who argued in The Art of Loving that people place too much importance on 'falling in love,' and not enough on learning how to 'stand in love.' Without denying that 'empty' forms of commitment do exist (Hatfield, Bensman, \& Rapson, 2012), in its fullest sense, prâgma arguably exemplifies this notion of 'standing in love.' It has its kinship in the Korean noun jeong, which depicts a deep affinity or connectedness that is not necessarily accompanied by romance. It is also reflected in the French verb s'apprivoiser, which literally means 'to tame,' but which in the context of 
Running head: A LEXICAL ANALYSIS OF LOVE

a deep relationship can depict a mutual process of accommodation, whereby both sides learn to trust and accept each other.

\section{Anánkē: Star-crossed love}

We come to the fifth and final type of romantic love - one that might be regarded as its deepest and most complete form, although it can also be associated with tragedy, as per the archetype of Shakespeare's Romeo and Juliet. While this type doesn't feature in Lee's (1977) typology - though agápe comes close - it is identified by Sternberg (1997) as 'consummate love,' involving the trinity of intimacy, passion and commitment. This type of love is strongly represented among the words analysed here. Interestingly, many allude to destiny and fate, capturing the sense that powerful forces guide its appearance in people's lives, hence the choice of anánkē as the overarching label. In classical Greek, anánkē represented a binding force or necessity, and similarly implied unshakable destiny, to the extent that the poet Simonides wrote that "Even the Gods don't fight against anánke”" (cited in Bowra, 1958, p.61). For instance, in Japanese, koi no yokan refers to the feeling on meeting someone that falling in love will be inevitable, while in Chinese yuán fèn describes a 'binding force' that impels a relationship ordained by destiny. These are augmented by words which, while not invoking fate, depict unshakable 'lifelong' forms of love, such as sarang in Korean.

\section{Agápē: Compassionate love}

The next form of love here is agápē. This featured in Lee's (1977) typology as a secondary type, a combination of érōs and storgē, involving charitable and 'selfless' love. The term is closely associated with Greek versions of the Bible, in which it is prominent as the kind of unconditional love that God was depicted as holding towards humanity. (The translators of the King James Bible chose to render agápē as charity, for various reasons, a rendering which many scholars have suggested is not ideal (Hitchens, 2011).) As such, Jesus implored his followers to emulate this in their relations with one another. Indeed, in the Christian tradition, 
agápē is valorised as pre-eminent among the theological virtues: in the words of St. Paul, "So faith, hope, love [agápē] abide, these three; but the greatest of these is love" (Revised Standard Version, 1952; 1 Corinthians 13:13). Thus, in its truest sense, agápē is not love directed exclusively towards select others. That is, a parent might feel unconditional, selfless love towards their child, such that they would sacrifice themselves to protect their progeny. However, in the fullest sense of the term, agápē depicts a more universal compassionate love, directed towards others 'in general.' There are many terms which pertain to this kind of love, including several expressing a sense of 'loving-kindness,' such as pittiarniq in Inuit, maitrī in Sanskrit, and gemilut hasadim in Yiddish. Related too are words concerning the virtue of showing kindness and hospitality to others, even (or especially) to strangers, from melmastia in Pashto to ubuntu in Nguni Bantu.

\section{Koinōnía: Momentary love}

This penultimate type tends to be overlooked or underappreciated in discussions around love, mainly because people usually only refer to love in the context of stable or enduring relationships. However, in recent years, an innovative theory proposed by Fredrickson (2013) - entitled 'Love 2.0' - identifies love with momentary micro-feelings of connection with people. Indeed, Fredrickson argues that this is love, and that the other forms, as discussed above, are rather elaborations of these fleeting intimacies. However, here this type is included as one form among many. The word selected to represent this form of love is koinonia, which pertains to feelings of communion, sharing, and intimacy. However, in contrast to the negotiated longevity of prâgma - discussed below - koinonia is at the other end of the temporal scale; not an absence of commitment per se, but an absence of extended duration at all. Rather, it is a momentary spark between people, such as a meaningful flash of eye contact, or a shared moment of 'participatory consciousness' (Lutz, 2009), e.g., as enjoyed by audiences at a captivating musical event. This momentary type of love is captured by the 
Running head: A LEXICAL ANALYSIS OF LOVE

French noun frisson, which depicts a sudden thrill, involving a potent combination of fear and excitement.

\section{Sébomai: Reverential love}

This final form of love is also not often included in prominent typologies, like Lee's (1977) or Sternberg's (1986). However, in some ways, it is the logical counterpart to agápē. Recall that agápe was viewed as the kind of benevolent, paternal love that God held towards humanity, which Jesus encouraged his followers to emulate. As such, in conceiving of an asymmetrical relationship between God and humankind, agápē expresses the love flowing 'down' from God. Correspondingly, this relationship has its concomitant 'upwards' form, a submissive stance of reverence and devotion. This is encapsulated by the Greek term sébomai, which means to stand in reverence, awe, and worship. This form of love combines the utmost of respect and devotion, together with darker elements such as fear, reflecting the power asymmetry of the dyad, which in the case of a relationship with God is essentially infinite (Johnson, 2016). Indeed, Keltner and Haidt (2003) describe awe as a "spiritual emotion" that exists in a powerful, rarefied zone "in the upper reaches of pleasure and on the boundary of fear" (p.297). A somewhat similar form of devotional love, found within the Hindu tradition, is expressed by the Sanskrit term bhakti. However, in that cultural context, devotion can potentially take on different emotional qualities to those usually found within Western traditions, such as intimacy; this point shall be addressed further in the discussion below. Relatedly, there are words which pertain to other kinds of persons - aside from Gods - that may be a focus of such love, like the Sanskrit term guru, which describes a revered spiritual teacher or guide. This type of devotional love can also be extended to secular persons - albeit that the love retains a quasi-religious fervour - such as music or screen idols, a Greek-derived word which is particularly apt, given that it originally referred usually to an image of a deity. 


\section{Discussion}

This paper has sought to extend the typologies of love previously formulated by Lee (1977) and Sternberg (1986). In this present study, 14 different types (or 'flavours') of love were identified. Again though, it should be emphasised that this typology does not imply that a given relationship can necessarily be pigeon-holed as exclusively constituting just one type; rather, partnerships may potentially be a blend of more than one flavour. To go beyond a merely descriptive typology, it will be helpful to understand the conceptual interrelationships between these different types. To that end, it is possible to group these 14 into four overarching thematic categories, as shown in figure 1 below: non-personal; caring; romantic; and transcendent. Moreover, each category can be understood as being driven by a specific motivation: appreciation; concern; desire; and self-transcendence.

[insert figure 1 about here]

First, there are three forms of non-personal love, i.e., not directed towards people, including love for experiences (meraki), objects (érōs), and places (chōros). With these forms, the fundamental dynamic appears to be appreciation: above all, the person takes pleasure or interest in the phenomenon in question (Carlson, 2002). They may of course also care for these items, but this is not necessarily the case. Nor is it the kind of deep concern and responsibility associated with love for family members, say. This brings us to the second category, caring love. This involves non-romantic forms of affection that tend to be reserved for friends (philia), family (storgē), and oneself (philautia). Here the fundamental dynamic is arguably concern, in the sense of being vested in the other person's welfare, with incumbent feelings of duty and responsibility (Myers, 1991). Third, there are five forms of romantic love: passionate (epithymia); playful (paixnidi); possessive or otherwise troubled (mania); sensible (prâgma); and 'star-crossed' (anánkē). Here the main dynamic is desire, i.e., physical and/or mental attraction, usually involving passion and sexual excitement 
(Luhmann, 1986). Finally, there are three forms of love which could be regarded as transcendent, in which the individual abrogates their own needs or concerns: compassionate (agápē), unitive (koinōnía), and reverential love (sébomai). With these, the main dynamic is self-transcendence, in that the person overcomes narrow self-pre-occupation, and is instead absorbed in feelings that yoke them to a broader or higher concern (Lomas, 2015b).

Thus, one can see that this schema considerably extends the earlier typologies of Lee (1977) and Sternberg (1986). For as useful as their earlier efforts were, those typologies were limited to love for people, and often (though not exclusively) romantic forms of love. As such, they do not account for the many ways in which people use the term 'love.' Speaking reflexively, I can, for instance, state that I love my wife, my parents, my brother and sister, my friends, London, David Bowie, ice cream, and swimming outdoors. Clearly, these are all different forms of love, as Lee and Sternberg would readily acknowledge. But there is no room in their schemas for the love I hold for those latter four items. But I do mean it when I say I love them, actively choosing this strong word over weaker verbs, such as 'to like' or 'to appreciate.'

One might wonder whether such an all-inclusive conception of love is necessarily helpful. After all, it could be argued that the concept of love is enriched through a degree of specificity and uniqueness. However, the prerogative of this paper is to reflect the way in which the term love functions in common discourse, where it covers a wide range of phenomena, as argued above. That said, this broader conception of love raises the question of the extent to which it differs from related stances such as liking. Ultimately, as alluded to previously, it seems the main way in which these can be distinguished is in terms of the strength of the passion. According to Sternberg (1987), many theories conceive of liking and loving as being regions along a spectrum, rather than separate, discrete categories. Both generally denote a stance of appreciation towards a phenomenon: milder forms are labelled 
liking; then, once a critical threshold is reached - which varies from person to person - a designation of love is deemed more appropriate.

Some scholars have attempted to stretch Lee's and Sternberg's models so that they can account for a greater variety of loving relationships. This is the case with Whang et al. (2004) for instance, who, as noted above, suggested that bikers genuinely feel érōs, mania and agápē in relation to their motorcycles. However, such attempts rather seem like they are straining to make the data (i.e., the way people talk about 'loving' motorcycles) fit the theory. Arguably, we will develop a better understanding of love if we allow the theory to emerge out of the data. This isn't to imply that Lee and Sternberg did not base their theories on data. It's just that they started with a limited conceptualisation of love, since their models were formulated on the basis of only three primary components - components which tend to be present in romantic love. However, as noted above, there is no a priori reason that love should only comprise three such components. Indeed, it was possible here to identify three further candidates that appear to warrant the status of primary components: care; connection; and appreciation. These can be considered primary in that their presence alone might still merit the use of 'love.' For instance, I might love a new song that I hear on the radio: this feeling is not characterised by Sternberg's components of passion, intimacy, or commitment, but just by aesthetic appreciation. As such, I have made a preliminary attempt to categorise the 14 types of love according to six primary components - Sternberg's trio of passion, intimacy, and commitment, plus care, connection, and appreciation - as outlined in table 1 below.

[insert table 1 about here]

The table also reflects the possibility that nearly all forms of love potentially have a destructive 'dark' side (Spitzberg \& Cupach, 1998). This potentiality was discussed above in relation to mania - which is by definition harmful - and to an extent paixnidi. However, most 
of the forms can likewise have unhealthy strains. On reflection, there appear to be at least three destructive factors that can render love as unhealthy. First, there is the potential for the focus of one's love to be objectified, i.e., treated as an object, without agency or dignity. Second, and relatedly, there is the possibility of treating this target as one's possession. Indeed, these two tend to go hand in hand. However, they are not necessarily identical. One could imagine scenarios in which a person is objectified but not necessarily viewed possessively, such as when people fantasise about celebrities. Conversely, it is possible to be possessive without objectifying, as might be found with an overbearing parent.

A third factor is the extent to which the object of love is appropriate for that type, or whether it is 'misdirected' according to prevailing norms. That is, love is a relational phenomenon, and cannot be appraised independently of its object. For each of the types, there is arguably an implicit set of people or phenomena who would usually - i.e., according to norms in most cultures - be deemed suitable loci for that type. If these 'natural' pairings are interfered with, it is usually regarded as problematic. To appreciate this point, consider the four overarching thematic categories, introduced above. From this schematic, one can appreciate that all 14 forms of love are not equivalent, nor are they interchangeable with respect to their focus. Or at least, if a person treats them as interchangeable, or the boundaries between the categories become blurred, this tends to be seen as problematic, and indeed as pathological. If, for instance, forms of romantic love are directed towards people or items associated with the other three categories, this is usually considered morally wrong and/or a classifiable pathology, with these inappropriate forms of cathexis referred to clinically as paraphilias (Kafka, 1994). Similarly, if a person is unable to differentiate feelings towards people from feelings towards objects, this is widely treated as characteristic of psychopathy, being evidence of dehumanisation and detachment (Ali \& Chamorro-Premuzic, 2010). As such, while this paper explored the merits of an expanded understanding of love, it is also 
vital to retain a sense of the crucial differences between its different forms. This is particularly the case with regard to who or what is the focus of a certain type of feeling.

Overall then, this paper represents a promising initiative in terms of expanding our understanding of love. However, there are limitations to the analysis which should be borne in mind. First, while untranslatable words have helped to illuminate the different types of love, the analysis does not provide a comprehensive picture of these words themselves. That is, like the term love, many of these words are themselves polysemous, incorporating a wealth of meanings. These meanings do not necessarily fit neatly within the specific types of love outlined above, for which the terms were used as examples. For instance, bhakti was included as an example of sébomai, i.e., devotional love for God. However, while it is not inaccurate to cite this as an instance of sébomai, bhakti also embeds feelings that, in the West, one might not usually associate with reverence for a deity, such as passion, intimacy, care, and connection (Kumar, 2010). Thus, bhakti cannot simply be classified as a form of devotional love, at least as far as this type of love is usually understood in Western contexts.

That said, in not fitting neatly into this conceptual schema, it could also be argued that terms like bhakti expand our current understanding of the different types of love. That is, one might suggest that the schema outlined here is somewhat Western-centric, being constructed by a scholar born, raised, and working in the UK. As such, it inevitably reflects Western ideas around love. For instance, its conception of devotional love has been influenced by JudeoChristian concepts and practices in this regard, which tend to emphasise qualities such as awe, respect, and emotional distance (Johnson, 2016). This stands in contrast to devotional ideas associated with traditions such as Hinduism, in which a greater level of intimacy is encouraged or permitted. Indeed, in the Vedanta teachings known as Ádvaita (or 'non-dual'), the individual self or soul - known as atman - is regarded as being of the same 'essence' or process as the Godhead, known as Brahman (Poonamallee, 2010). In that context, one may 
have a different conception of reverential love, compared to traditions like Judaism and Christianity, where there is usually a vast ontological separation between the person and God. However, rather than such considerations being necessarily problematic for the theoretical schema above, these possibilities may help to enrich it. That is, over the coming years, more comprehensive analyses of relevant untranslatable words can help enhance our understanding of the different types of love identified here.

A second point of consideration is the assignation of specific types of love as being variously constituted by the six components outlined in table 1 . It must be acknowledged that this assignation is merely hypothetical at this stage. It is based on a close reading of the words that helped create the category, together with reflections based on personal experience. Future research will be required to substantiate or otherwise refine these assignations. Relatedly, the 14 types of love identified here are not necessarily exhaustive. Indeed, given that Sternberg's (1986) three primary components gave rise to seven possible permutations, with six primary components the number of theoretical combinations rises to 63 ! Without implying that there are 63 different types of love, it is possible that other forms of love remain to be identified. Indeed, it is hoped that this paper will provide the stimulus for just such a research program, aiming to both better understand the 14 types identified here (e.g., in terms of how they load on the six hypothesised components), and to ascertain whether these should be joined by any other distinct types.

Thus, while the analysis above is promising, its conclusions are merely tentative at this stage. It will be instructive to investigate these ideas further through both qualitative and quantitative methods. Qualitative enquiry will enable a better understanding of the words used here to generate the various types of love. For instance, in-depth interviews with people who have experiential familiarity with the notion of bhakti will help to shed more light on this concept, and by extension, also enrich our appreciation of reverential love. Such analyses 
Running head: A LEXICAL ANALYSIS OF LOVE

could then be augmented by quantitative assessment, particularly factor analysis. One longterm goal would be to construct psychometric scales relevant to each of the types of love.

Doing so will help establish their construct validity, tease out their nuances, and facilitate an understanding of how they interrelate. Likewise, it would be instructive to examine the biological substrates of these different forms. As per the neural correlates of consciousness paradigm (Fell, 2004), it is possible that these types will have different neurophysiological patterns associated with them. Should such signatures be identified, this will help to further establish whether these 14 types do indeed represent distinct forms (or 'flavours') of love. As such, it is hoped that the current paper will stimulate a research agenda that allows us to better understand love, thus doing justice to this most cherished and yet polysemous of concepts. 


\section{References}

Albert, N., Merunka, D., \& Valette-Florence, P. (2008). When consumers love their brands: Exploring the concept and its dimensions. Journal of Business Research, 61(10), 1062-1075. doi: http://dx.doi.org/10.1016/j.jbusres.2007.09.014

Ali, F., \& Chamorro-Premuzic, T. (2010). The dark side of love and life satisfaction: Associations with intimate relationships, psychopathy and Machiavellianism. Personality and Individual Differences, 48(2), 228-233. doi:

10.1016/j.paid.2009.10.016

Aristotle. (350BCE/2000). Nicomachean ethics (R. Crisp Ed.). Cambridge: Cambridge University Press.

Aristotle. (1954). Rhetoric (W. R. Roberts, Trans.). New York: The Modern Library Press.

Berscheid, E. (2010). Love in the fourth dimension. Annual Review of Psychology, 61, 1-25.

Bowra, C. M. (1958). The Greek experience. New York: W. P. Publishing Company.

Brenk, F. E. (1988). Plutarch's "Erotikos": The drag down pulled up. Illinois Classical Studies, 13(2), 457-471.

Browning, D. S. (2002). Science and Religion on the Nature of Love. In S. G. Post, L. G. Underwood, J. P. Schloss \& W. B. Hurlbut (Eds.), Altruism and altruistic love: Science, philosophy, and religion in dialogue (pp. 335-345). Oxford: Oxford University Press.

Carlson, A. (2002). Aesthetics and the environment: The appreciation of nature, art and architecture. New York: Routledge.

Cooper, L. D. (1998). Rousseau on self-love: What we've learned, what we might have learned. Review of Politics, 60, 661-684. 
Costa, P. T., \& McCrae, R. R. (1992). Normal personality assessment in clinical practice: The NEO Personality Inventory. Psychological Assessment, 4(1), 5-13. doi: 10.1037/10403590.4 .1 .5

Coupland, N., Bishop, H., \& Garrett, P. (2003). Home truths: Globalisation and the iconising of Welsh in a Welsh-American newspaper. Journal of Multilingual and Multicultural development, 24(3), 153-177.

Engel, G., Olson, K. R., \& Patrick, C. (2002). The personality of love: Fundamental motives and traits related to components of love. Personality and Individual Differences, 32(5), 839-853. doi: http://dx.doi.org/10.1016/S0191-8869(01)00090-3

Fell, J. (2004). Identifying neural correlates of consciousness: The state space approach. Consciousness and Cognition, 13(4), 709-729. doi: 10.1016/j.concog.2004.07.001

Fredrickson, B. L. (2013). Love 2.0. New York, NY: Hudson Street Press.

Fromm, E. (1956/2000). The art of loving: The centennial edition. New York: Bloomsbury Publishing.

Gabriel, B. (2004). The unbearable strangeness of being: Edgar Reitz's Heimat and the ethics of the unheimlich. In B. Gabriel \& S. Ilcan (Eds.), Postmodernism and the ethical subject. New York: McGill-Queen's Press-MQUP.

Hatfield, E., Bensman, L., \& Rapson, R. L. (2012). A brief history of social scientists' attempts to measure passionate love. Journal of Social and Personal Relationships, 29(2), 143-164.

Hendrick, C., \& Hendrick, S. (1986). A theory and method of love. Journal of Personality and Social Psychology, 50(2), 392-402.

Hindy, C. G., \& Schwarz, J. C. (1994). Anxious romantic attachment in adult relationships. In M. B. S. W. H. Berman (Ed.), Attachment in adults: Clinical and developmental perspectives (pp. 179-203). New York, NY, US: Guilford Press. 
Hitchens, C. (2011). Arguably: Selected prose. Atlantic Books: London.

Hofstadter, A., \& Kuhns, R. (Eds.). (2009). Philosophies of art and beauty: Selected readings in aesthetics from Plato to Heidegger: University of Chicago Press.

Isaacs, D. (2015). Parental love. Journal of paediatrics and child health, 51(3), 241-242.

Johnson, D. (2016). God is watching you: How the fear of God makes us human. New York: Oxford University Press.

Kafka, M. P. (1994). Paraphilia-related disorders — common, neglected, and misunderstood. Harvard Review of Psychiatry, 2(1), 39-40. doi: 10.3109/10673229409017112

Keltner, D., \& Haidt, J. (2003). Approaching awe, a moral, spiritual, and aesthetic emotion. Cognition \& Emotion, 17(2), 297-314.

Kinsley, D. R. (1974). Creation as play in Hindu spirituality. Studies in Religion/Sciences Religieuses, 4(2), 108-119.

Kumar, S. S. (2010). Bhakti - the yoga of love: Trans-rational approaches to peace studies. Berlin: LIT Verlag Münster.

Lee, J. A. (1973). The colors of love: An exploration of the ways of loving. Don Mills, Ontario: New Press.

Lee, J. A. (1977). A typology of styles of loving. Personality and Social Psychology Bulletin, 3(2), 173-182. doi: 10.1177/014616727700300204

Lomas, T. (in press a). The palette of ambivalent emotions: A cross-cultural lexical analysis. Qualitative Research in Psychology.

Lomas, T. (in press b). The dynamics of spirituality: A cross-cultural lexical analysis. Psychology of Religion and Spirituality.

Lomas, T. (in press c). The spectrum of positive affect: A cross-cultural lexical analysis. International Journal of Wellbeing. 
Lomas, T. (2015a). Positive cross-cultural psychology: Exploring similarity and difference in constructions and experiences of wellbeing. International Journal of Wellbeing, 5(4), 60-77. doi: 10.5502/ijw.v5i4.3

Lomas, T. (2015b). Self-transcendence through shared suffering: A transpersonal theory of compassion. Journal of Transpersonal Psychology, 27(2), 168-187.

Lomas, T. (2016). Towards a positive cross-cultural lexicography: Enriching our emotional landscape through 216 'untranslatable' words pertaining to wellbeing. The Journal of Positive Psychology. doi: 10.1080/17439760.2015.1127993

Luhmann, N. (1986). Love as passion: The codification of intimacy. Cambridge, MA: Harvard University Press.

Lutz, J. (2009). Flow and sense of coherence: Two aspects of the same dynamic? Global Health Promotion, 16(3), 63-67. doi: 10.1177/1757975909339774

Mallandain, I., \& Davies, M. F. (1994). The colours of love: Personality correlates of love styles. Personality and Individual Differences, 17(4), 557-560. doi: http://dx.doi.org/10.1016/0191-8869(94)90092-2

Montgomery, M. J., \& Sorell, G. T. (1997). Differences in love attitudes across family life stages. Family Relations, 55-61.

Murstein, B. I. (1988). A taxonomy of love. In R. Sternberg \& M. Barnes (Eds.), The Psychology of Love (pp. 13-37). New Haven, CT: Yale University Press.

Myers, F. R. (1991). Pintupi country, Pintupi self: Sentiment, place, and politics among Western desert Aborigines. Los Angeles: University of California Press.

Poonamallee, L. (2010). Advaita (non-dualism) as metatheory: A constellation of ontology, epistemology, and praxis. Integral Review, 6, 190-200.

Rousseau, J.-J. (1762/2008). The social contract. New York: Cosimo Classics.

Sapir, E. (1929). The status of linguistics as a science. Language, 207-214. 
Sarwer, D. B., Kalichman, S. C., Johnson, J. R., Early, J., \& Ali, S. A. (1993). Sexual aggression and love styles: An exploratory study. Archives of Sexual Behavior, 22(3), $265-275$.

Shaver, P. R., \& Hazan, C. (1988). A biased overview of the study of love. Journal of Social and Personal Relationships, 5(4), 473-501. doi: 10.1177/0265407588054005

Shimp, T. A., \& Madden, T. J. (1988). Consumer-object relations: A conceptual framework based analogously on Sternberg's triangular theory of love. Advances in Consumer Research, 15(1), 163-168.

Sperling, M. B., \& Berman, W. H. (1991). An attachment classification of desperate love. Journal of Personality Assessment, 56(1), 45-55.

Spitzberg, B. H., \& Cupach, W. R. (1998). The dark side of close relationships. London: Routledge.

Sternberg, R. J. (1986). A triangular theory of love. Psychological Review, 93(2), 119-135. doi: 10.1037/0033-295X.93.2.119

Sternberg, R. J. (1987). Liking versus loving: A comparative evaluation of theories. Psychological Bulletin, 102(3), 331-345. doi: 10.1037/0033-2909.102.3.331

Sternberg, R. J. (1997). Construct validation of a triangular love scale. European Journal of Social Psychology, 27(3), 313-335.

Tennov, D. (1998). Love and limerence: The experience of being in love. London: Scarborough House.

Tillich, P. (1954). Being and love. Pastoral Psychology, 5(3), 59-60.

Underhill, E. (1941/2015). Mysticism: A study in the nature and development of man's spiritual consciousness: Aeterna Press.

Walter, E. V. (1988). Placeways: A theory of the human environment. London: UNC Press Books. 
Running head: A LEXICAL ANALYSIS OF LOVE

Whang, Y.-O., Allen, J., Sahoury, N., \& Zhang, H. (2004). Falling in love with a product: The structure of a romantic consumer-product relationship. Adv Consum Res, $31(320-327)$.

Whorf, B. L. (1940). Science and linguistics. Technology Review, 42(6), 229-231, 247-248.

Wierzbicka, A. (1999). Emotions across languages and cultures: Diversity and universals. Cambridge: Cambridge University Press.

Wilkins, R., \& Gareis, E. (2006). Emotion expression and the locution "I love you": A crosscultural study. International Journal of Intercultural Relations, 30(1), 51-75. doi: http://dx.doi.org/10.1016/j.ijintrel.2005.07.003 
Running head: A LEXICAL ANALYSIS OF LOVE

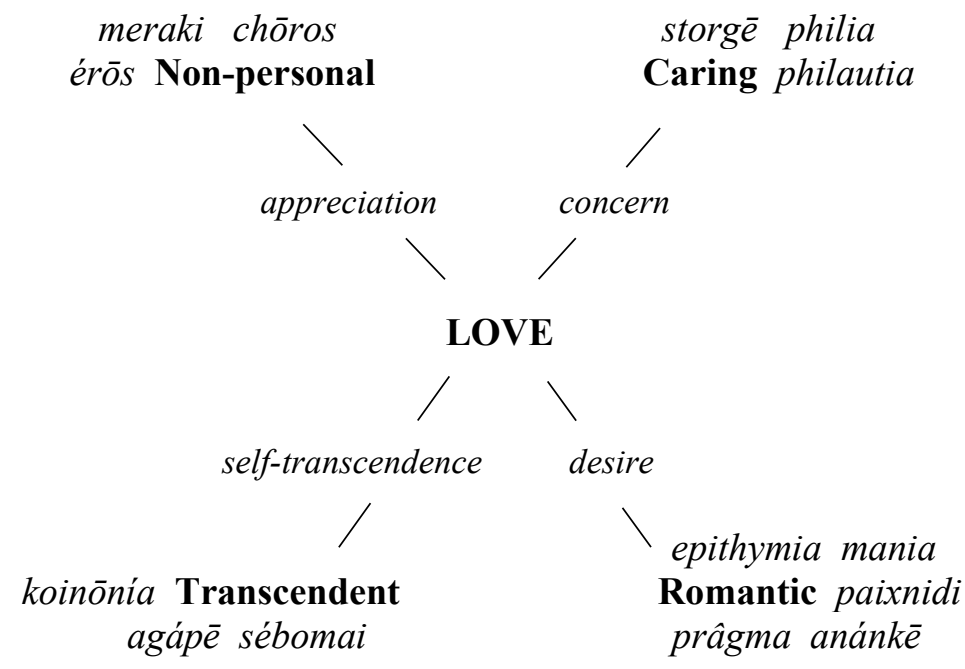

Figure 1. The 14 types of love, aggregated into 4 categories, together with their fundamental drivers. 
Running head: A LEXICAL ANALYSIS OF LOVE

\begin{tabular}{|c|c|c|c|c|c|c|c|c|c|}
\hline \multicolumn{7}{|c|}{ The components of love } & \multicolumn{3}{|c|}{ The destructive factors } \\
\hline & Intimacy & Passion & Commitment & Care & Appreciation & Connection & $\begin{array}{l}\text { Objecti- } \\
\text { fication }\end{array}$ & $\begin{array}{l}\text { Possess- } \\
\text { iveness }\end{array}$ & Misdirected \\
\hline Meraki & & $x$ & & $x$ & $x$ & & $?$ & $?$ & $?$ \\
\hline Érōs & & $x$ & & & $x$ & $x$ & $?$ & $?$ & $?$ \\
\hline Chōros & & & $x$ & & $x$ & $x$ & $?$ & $?$ & $?$ \\
\hline Philia & $x$ & & $x$ & $x$ & & $x$ & $?$ & $?$ & $?$ \\
\hline Philautia & & & $x$ & $x$ & $x$ & & $?$ & $?$ & $?$ \\
\hline Storgē & $x$ & & $x$ & $x$ & & $x$ & $?$ & $?$ & $?$ \\
\hline Epithymia & $x$ & $x$ & & & & & $?$ & $?$ & $?$ \\
\hline Paixnidi & & $x$ & & & & & $?$ & $?$ & $?$ \\
\hline Mania & & $x$ & $x$ & & $x$ & & $x$ & $x$ & $?$ \\
\hline Prâgma & & & $x$ & & $x$ & & $?$ & $?$ & $?$ \\
\hline Anánkē & $x$ & $x$ & $x$ & $x$ & $x$ & $x$ & $?$ & $?$ & $?$ \\
\hline Agápē & $x$ & & $x$ & $x$ & & & & & \\
\hline Koinōnía & $x$ & & & & & $x$ & $?$ & $?$ & $?$ \\
\hline Sébomai & & & $x$ & & $x$ & & $?$ & $?$ & $?$ \\
\hline
\end{tabular}

Table 1. The 14 types of love, illustrating their loadings on the 6 hypothesised components, and the 3 hypothesised destructive factors 